\title{
CORRIGENDUM
}

\section{Publics and biobanks: Pan-European diversity and the challenge of responsible innovation}

George Gaskell, Herbert Gottweis, Johannes Starkbaum, Monica M Gerber, Jacqueline Broerse, Ursula Gottweis, Abbi Hobbs, Ilpo Helén, Maria Pashou, Karoliina Snell and Alexandra Soulier

European Journal of Human Genetics (2013) 21, 121; doi:10.1038/ejhg.2012.236

Correction to: European Journal of Human Genetics advance online publication, 6 June 2012; doi:10.1038/ejhg.2012.104

Since the publication of this article one of the authors, Herbert Gottweis, has asked for an additional affiliation to be added. This has now been added and the amended article appears in this issue. The HTML and online PDF versions have also been amended and now carry the additional affiliation. 